\title{
Exchange Rate Pass-Through in Brazil: A Markov Switching DSGE Estimation for the Inflation Targeting Period
}

Fabrizio Almeida Marodin, University of California Irvine fmarodin@uci.edu

Marcelo Savino Portugal, Universidade Federal do Rio Grande do Sul msp@ufrgs.br

This paper investigates the nonlinearity of exchange rate passthrough in the Brazilian economy during the inflation targeting period (2000-2018) using a Markov Switching new Keynesian DSGE model. We find evidence of two distinct regimes for exchange rate passthrough and for the volatility of shocks to inflation. Under the so-called 'normal' regime, the long-run pass-through to consumer prices inflation is estimated as almost zero, only 0.00057 of a percentage point given a $1 \%$ exchange rate shock. In comprasion, the expected pass-through to inflation under a 'crisis' regime is 0.1035 of a percentage point, for the same exchange rate shock. These results allow us to identify four distinct cycles for exchange rate pass-through during the inflation targeting period in Brazil, and suggest that higher central bank credibility and anchored inflation expectations may be related to lower levels of pass-through.

Keywords: exchange-rate pass-through, new Keynesian model, DSGE, regime switching, Markov chain, central bank credibility

JEL Codes: E31, F31, C3
Citation: Marodin, F. A. and Portugal, M. S. (2019). Exchange Rate Pass-Through in Brazil: A Markov Switching DSGE Estimation for the Inflation Targeting Period. Russian Journal of Money and Finance, 78(1), pp. 36-66.

doi: 10.31477/rjmf.201901.36

\section{Introduction}

This paper assesses exchange rate pass-through to inflation in the Brazilian economy during the inflation targeting and floating exchange rate period using a Markov Switching (MS) new Keynesian Dynamic Stochastic General Equilibrium (DSGE) model. Our aim is to check for nonlinear behaviour of the exchange rate pass-through using an innovative methodological framework, given the possibility it could further amplify inflation during periods of external sector distress. 
The research is aligned with the recent literature in structural parameter drifting, or nonlinear behaviour of structural parameters. According to Hamilton (2014), nonlinear mechanisms that trigger macroeconomic regime shifts are one of the most noteworthy contemporary issues in macroeconomics. Contemporary economies are subject to remarkable changes, recurrent crises, recessions, and financial stress. These events produce 'dramatic breaks' in macroeconomic time series and, consequently, lead agents to form expectations under different regimes.

The traditional approach to analysing changes in structural parameters is based on Hamilton's (1989) business cycle model. In this method, some parameters in the reduced form linear model may vary freely according to a Markov process. Sims and Zha (2006) is a pioneering work on modelling regime shifts in US monetary policy using a structural MS-VAR model. However, less work has been done with structural new Keynesian, or Dynamic Stochastic General Equilibrium (DSGE), models with regime-switching mechanisms, as this topic is relatively new. Justiniano and Primicieri (2008), for example, assess regime switching only in the volatility of shocks, whereas Fernández-Villaverde et al. (2010), Bianchi (2013), Baele et al. (2015), and Iboshi (2016) focus on changes in the Taylor rule parameters and their consequences for macroeconomic equilibrium. These studies are usually interested in identifying periods in which US monetary policy takes 'active' vs. a 'passive' approach to inflation.

The rationale for this paper derives from the risk of underestimating the effect of an exchange rate shock to inflation when DSGE models are used. The international literature has found meaningful evidence of nonlinear exchange rate pass-through in several developing and developed economies (Albuquerque and Portugal, 2005; Correa and Minella, 2010; Holmes, 2009; Khemiri and Ali, 2013, Donayre and Panovska, 2016; Baharumshah et al., 2017). However, to the best of our knowledge, there is no published work on the estimation of DSGE models allowing for non-linear exchange rate pass-through. Policymakers using linearised DSGE models to forecast inflation may incur greater than expected forecast error, especially during external sector crisis events, where policy decisions are of the highest importance.

Nearly all the estimated DSGE models for the Brazilian economy have assumed constant parameters (da Silveira, 2008; Furlani et al., 2010; De Castro et al., 2015; Palma and Portugal, 2014). An exception is Gonçalves et al. (2016), who investigated regime switching in the Taylor rule. On the other hand, a rich strand of research evaluates changes in the structural parameters of the Brazilian economy by applying conventional regime switching models such as Hamilton (1989). Fasolo and Portugal (2004) find changes in the Phillips curve parameters whereas Vieira and Pereira (2013) describe differences in business cycle dynamics. More recently, Rodrigues and Mori (2015) have identified different monetary policy regimes using a model with changes in the Taylor rule parameters, and Oliveira 
and Feijó (2015) have investigated the nonlinearity between unemployment and inflation using a Phillips curve with Markov switching. We therefore assume that the paucity of empirical studies on regime switching new Keynesian DSGE models in Brazil is due mainly to their recent development rather than to the belief that Brazil's economy is subject to fixed structural parameters. Hence, the contribution of this paper is to fill this gap and propose a novel empirical strategy to quantify the effect of non-linear exchange rate pass-through in a DSGE estimation.

The nonlinear behaviour of exchange rate pass-through is theoretically confirmed by Dixit (1989) and Taylor (2000). Dixit (1989) attributes differences in pass-through to firms' decision-making uncertainty. The more uncertain firms are about the steadinessy of the exchange rate, the greater their incentive to adopt a wait-and-see strategy before adjusting prices, given adjustment and reputation costs. Thus, if the exchange rate shock is seen as permanent, agents will respond with a higher pass-through to prices, unlike in the case of temporary shocks. Taylor (2000) proposes a different argument, in which differences in the level of pass-through are related to price rigidity. In periods of higher inflation, firms transfer their costs more frequently, including costs associated with imported inputs, as overall price rigidity is reduced. Figueiredo and Gouvea (2011) support Taylor's viewpoint and provide empirical evidence that heterogeneity in the passthrough in Brazil is related to the level of price rigidity.

As mentioned above, there is a well-established body of empirical literature on variable, or nonlinear, exchange rate pass-through, but this literature has not yet touched on DSGE estimation. Goldfajn and Werlang (2000) confirm that the intensity of pass-through in cases of exchange rate depreciation is not fixed, but depends upon a series of economic state variables. The key factors would be the cyclical component of output, initial overvaluation of the real exchange rate, the initial inflation rate, and the level of economic openness. Albuquerque and Portugal (2005) affirm that the intensity of exchange rate pass-through in the Brazilian economy varies over time and depends on macroeconomic factors, a statement which is also supported by Tombini and Alves (2006). Minella et al. (2003) and Kohlscheen (2010) affirm that exchange rate volatility is associated with variance in inflation and with higher passthrough. Moreover, the nonlinear or asymmetric behaviour of exchange rate pass-through is verified in the empirical studies undertaken by Correa and Minella (2010), Nogueira Jr (2010) and Pimentel et al. (2016). In other countries, Holmes (2009) and Khemiri and Ali (2013) assess regime switching in exchange rate pass-through by means of regressions based on the Phillips curve for New Zealand and Tunisia, respectively. Donayre and Panovska (2016) gather strong evidence of a nonlinear relationship between pass-through and economic activity for Canada and Mexico. In particular, the authors find a higher passthrough in expansionary periods, corroborating Goldfajn and Werlang (2000). 
The influence of the macroeconomic environment and of inflation stability on the observations of lower pass-through is also demonstrated by Winkelried (2014) in an empirical study for Peru.

In this paper, our goal is to estimate a basic new Keynesian DSGE model subject to regime switching in the exchange rate pass-through parameter and in the volatility of shocks to inflation by applying and developing the methods developed by Baele et al. (2015). One of the peculiarities of this method is the use of survey data on market expectations, which relaxes the assumption of rational expectations and, at the same time, simplifies model solution and estimation. Baele et al. (2015) suggest Cho's (2014) recursive solution method for regimeswitching rational expectations models, which circumvents some of the problems of convergence observed in Farmer et al. (2011). We take a different approach to Baele et al. (2015), who investigate regime switching in the monetary policy rule; our focus is instead on exchange rate pass-through. We therefore expand the original model by adding new elements to the AS curve and a new equation for exchange rate dynamics.

The MS model estimation, using the sample from 2000 to 2015, allows us to identify two possible regimes for exchange rate pass-through and the volatility of shocks to inflation. During a 'normal' cycle, the expected long-run pass-through to consumer prices inflation is very close to zero. We estimate a change of only 0.00057 of a percentage point given a $1 \%$ shock to the level of the exchange rate. In comprasion, the expected effect on inflation during a 'crisis' cycle is much higher, 0.1035 of a percentage point, given the same exchange rate shock. In addition, we confirm that the volatility of shocks to inflation is larger during the 'crisis' period. The MS model outperforms the linear model according to several comparison criteria. In the last part of the paper, we present a prediction exercise for the years 2016 to 2018Q2 that offers further insight into the relationship between central bank credibility and the pass-through regime. We consider these results to be of use for enriching models of inflation forecasting and addressing economic policy analysis more precisely during periods of distress.

The paper is organised into five sections, including this introduction. Section 2 describes the basic new Keynesian model and its extensions, introduces regime switching, assesses the equilibrium conditions and presents our identification strategy. Section 3 presents the data and the estimation method. Section 4 describes the results and their implications. Finally, Section 5 makes some concluding remarks.

\section{The Model}

This section describes the basic macroeconomic model, with the introduction of exogenous exchange rate shocks. We expand the model by adding a regime- 
switching mechanism. We then assess the rational expectations equilibrium and, finally, describe our strategy for including survey expectations.

\subsection{The new Keynesian model}

Consider the benchmark new Keynesian model with three variables as in Baele et al. (2015):

$$
\begin{array}{ll}
\pi_{t}=\delta E_{t} \pi_{t+1}+(1-\delta) \pi_{t-1}+\lambda y_{t}+\epsilon_{\pi, t} & \epsilon_{\pi, t} \sim N\left(0, \sigma_{A S}^{2}\right), \\
y_{t}=\mu E_{t} y_{t+1}+(1-\mu) y_{t-1}-\phi\left(i_{t}-E_{t} \pi_{t+1}\right)+\epsilon_{y, t} & \epsilon_{y, t} \sim N\left(0, \sigma_{I S}^{2}\right), \\
i_{t}=\rho_{i} i_{t-1}+\left(1-\rho_{i}\right)\left[\beta E_{t} \pi_{t+1}+\gamma y_{t}\right]+\epsilon_{i, t} & \epsilon_{i, t} \sim N\left(0, \sigma_{M P}^{2}\right),
\end{array}
$$

where $\pi_{t}$ is the inflation rate, $y_{t}$ is the output gap and $i_{t}$ is the nominal interest rate. The operator $E_{t}$ refers to conditional expectations. Each equation is amenable to unexpected shocks: $\epsilon_{\pi, t}$ is the aggregate supply shock (AS shock); $\epsilon_{y, t}$ is the aggregate demand shock (IS shock); and $\epsilon_{i, t}$ is the monetary policy shock (MP shock).

As for the structural parameters of the model, $\delta$ and $\mu$ stand for the forwardlooking behavior of firms (AS curve) and consumers (IS curve), respectively. The model allows for endogenous persistence if these parameters are different from 1 , with weight attached to the past values of each variable. Parameter $\lambda$ is the response of inflation to the output gap, while $\phi$ is the response of output to the real interest rate. The monetary authority's reaction function is a Taylor rule with smoothing parameter $\rho_{i}$, which reacts to inflation expectations with response $\beta$ and to deviations in output gap with parameter $\gamma$. It is assumed that monetary policy does not react to temporary shocks, which affect only the current inflation rate, not its future path.

The equations presented in this simple rational expectations (RE) model are derived from the first-order log-linearised conditions of the optimisation problems of each representative agent: consumers, firms, and the monetary authority. The model describes the dynamics of endogenous macroeconomic variables, in which current decisions are a function of future expectations for these variables and their past values. As a closed-economy model, it does not deal with exchange rate pass-through, a problem which we have found two alternatives to circumvent.

The first option would be to adopt the full dynamics of a small open economy model, such as Adolfson et al. (2007). Adding the regime-switching and transition probability parameters would result in an even more complex specification, with dozens of parameters to be estimated or calibrated. Since our focus is on a relatively short time period, we chose a less complex strategy. We model exchange rate shock as an unexpected change in the price of imported 
inputs, which, on impact, affects only the supply curve. In this way, we prioritise direct effects on inflation by adjusting of input prices as a consequence of exchange rate fluctuations. We disregard indirect effects on aggregate demand, such as changes in the relative prices of domestic versus imported goods, or the effect on the domestic interest rate. We have two justification for this. First, exchange rate depreciations in relatively closed economies, such as Brazil, tend to cause relatively smaller changes in the spending shares of domestic versus imported goods. This argument is made by Albuquerque and Portugal (2005) and discussed in Goldfajn and Werlang (2000). Second, estimation of a model using short observed time series and multiple regimes would be hindered as the number of parameters increases, making the endeavour impractical.

We define $\Delta e$ as the first difference of the nominal price of foreign currency $e$, and $\kappa$ as the effect on inflation (i.e. the exchange rate pass-through). The Phillips curve in equation (1a) thus becomes:

$$
\begin{aligned}
\pi_{t}=\delta E_{t} \pi_{t+1}+(1-\delta) \pi_{t-1}+\lambda y_{t}+\kappa \Delta e_{t}+\epsilon_{\pi, t} & \\
& \epsilon_{\pi, t} \sim N\left(0, \sigma_{A S}^{2}\right) .
\end{aligned}
$$

We assume that exchange rate fluctuations at time $t$ will affect inflation with a lag, following empirical arguments (Goldfajn and Werlang, 2000). The appropriate number of lags will be checked upon estimation. In addition, we assume that change in the exchange rate follows a first-order autoregressive process. We add a fourth equation to the model to describe the path of $\Delta e_{t}$, where $\epsilon_{e, t}$ is an identically-distributed exogenous exchange rate shock. The model is then represented, with one possible lag in the pass-through, as:

$$
\begin{array}{cc}
\pi_{t}=\delta E_{t} \pi_{t+1}+(1-\delta) \pi_{t-1}+\lambda y_{t}+\kappa_{1} \Delta e_{t-1}+\epsilon_{\pi, t} \\
y_{t}=\mu E_{t} y_{t+1}+(1-\mu) y_{t-1}-\phi\left(i_{t}-E_{t} \pi_{t+1}\right)+\epsilon_{y, t} \sim N\left(0, \sigma_{A S}^{2}\right) \\
i_{t}=\rho_{i} i_{t-1}+\left(1-\rho_{i}\right)\left[\beta E_{t} \pi_{t+1}+\gamma y_{t}\right]+\epsilon_{i, t} \sim N\left(0, \sigma_{I S}^{2}\right), \\
\Delta e_{t}=\rho_{e} \Delta e_{t-1}+\epsilon_{e, t} \sim N\left(0, \sigma_{M P}^{2}\right), \\
\epsilon_{e, t} \sim N\left(0, \sigma_{e}^{2}\right) .
\end{array}
$$

Our model differs from that of Baele et al. (2015) in equation (1), where we include the supply shock, and in equation (4), where we include the exchange rate path. Note that the Phillips curve represented by equation (1) is similar to the specifications used in previous studies on exchange rate pass-through in the 
Brazilian economy, such as Carneiro et al. (2004), Correa and Minella (2010), Tombini and Alves (2006), and Nogueira Jr (2010). Our approach differs, however, in that it considers cross-equation structural and equilibrium constraints derived from model-consistent expectations. ${ }^{1}$

In matrix notation, the model can be written as:

$$
A X_{t}=B E_{t} X_{t+1}+D X_{t-1}+\epsilon_{t} \quad \epsilon_{t} \sim N(0, \Sigma)
$$

Here, $X_{t}$ is the vector of macroeconomic variables and $\epsilon_{t}$ is the vector of structural shocks. Matrices $A, B, D$ contain the values of the structural parameters and $\Sigma$ represents the diagonal matrix with the variances of $\epsilon_{t}$. In our case, we have $X_{t}=\left[\pi_{t} y_{t} i_{t} \Delta e_{t}\right]^{\prime}$.

We follow Baele et al. (2015), taking into account that the rational expectations equilibrium (REE) of the model depends solely on minimal set of state variables, also known as the fundamental solution. The solution to model (5) follows the VAR (1) law of motion as in (6), where matrices $\Omega$ and $\Gamma$ are highly nonlinear functions of the structural parameters:

$X_{t}=\Omega X_{t-1}+\Gamma \epsilon_{t}$

$\epsilon_{t} \sim N(0, \Sigma)$

A model in this format can be solved by several methods, such as Sims (2002) or Cho and Moreno (2011). The inclusion of regime shifts in the model, however, requires a new characterisation of the rational expectations equilibrium.

We use the identification and estimation strategy proposed by Baele et al. (2015), which employs observed survey-based expectations, instead of assuming that rational expectations are not observed, but are part of the states to be estimated. The use of survey-based expectations for the estimation of new Keynesian models is rather uncommon, although it is relatively simple. Admittedly, market surveys may exhibit missing information bias or reflect the opportunistic behaviour of agents. Nevertheless, for Baele et al. (2015), survey-based expectations represent the different perceptions of economic agents based on a potentially richer set of information, and hence could be useful in improving estimation. The authors mention the high predictive power of surveys conducted with professional forecasters. In Brazil, the inflation forecast exercise by Altug and Çakmakli (2016) does indeed confirm the high predictive power of survey-based expectations. On the practical side, as will be seen below, calculation of the likelihood function and identification of regime shifts become much easier with this method, since a smaller number of states variables are considered unobserved.

\footnotetext{
${ }^{1}$ Some small open-economy models include exchange rate variation in the Taylor rule, for example Furlani et al. (2010). Other single-equation estimations of the Central Bank of Brazil reaction function, such as Rodrigues and Mori (2015), find statistical significance for the reaction to the exchange rate, during some periods of time. We have tried this type of specification for equation (3). However, we did not find stable solutions to the rational expectations model in this case.
} 


\subsection{Introducing regime switching}

We allow two possible regimes for both effect of the exchange rate on inflation, and the volatility of structural shocks to the aggregate supply curve. We thus define the discrete unobserved variable $S_{t}$, which takes on two possible values $S_{t}^{\pi}=[0,1]$ and serves as an indicator of the state of the economy in period $t$. The variable $S_{t}$ evolves according to a first-order Markov process, where $P\left[S_{t}=0 \mid S_{t-1}=0\right]=p_{00} ; P\left[S_{t}=1 \mid S_{t-1}=0\right]=p_{10}=\left(1-p_{00}\right) ; P\left[S_{t}=1 \mid S_{t-1}=1\right]=p_{11}$; $P\left[S_{t}=0 \mid S_{t-1}=1\right]=p_{01}=\left(1-p_{11}\right)$. This model is called fixed transition probabilities (Hamilton, 1989; Kim and Nelson, 1999).

The MS model is written as:

$$
\begin{aligned}
& \pi_{t}=\delta E_{t} \pi_{t+1}+(1-\delta) \pi_{t-1}+\lambda y_{t}+\kappa_{1 S_{t}} \Delta e_{t-1}+\epsilon_{\pi, t} \\
& \epsilon_{\pi, t} \sim N\left(0, \sigma_{A S}^{2}\left(S_{t}^{\pi}\right)\right), \\
& y_{t}=\mu E_{t} y_{t+1}+(1-\mu) y_{t-1}-\phi\left(i_{t}-E_{t} \pi_{t+1}\right)+\epsilon_{y, t} \\
& \epsilon_{y, t} \sim N\left(0, \sigma_{I S}^{2}\right), \\
& i_{t}=\rho_{i} i_{t-1}+\left(1-\rho_{i}\right)\left[\beta E_{t} \pi_{t+1}+\gamma y_{t}\right]+\epsilon_{i, t} \quad \epsilon_{i, t} \sim N\left(0, \sigma_{M P}^{2}\right) \text {, } \\
& \Delta e_{t}=\rho_{e} \Delta e_{t-1}+\epsilon_{e, t} \quad \epsilon_{e, t} \sim N\left(0, \sigma_{e}^{2}\right) .
\end{aligned}
$$

Note that the regime shift is considered only in the first equation (aggregate supply) in the parameters $\kappa_{1 S_{t}}$, representing exchange rate pass-through, and $\operatorname{Var}\left(\epsilon_{\pi, t} \mid X_{t-1} S_{t}^{\pi}\right)=\sigma_{A S}^{2}\left(S_{t}^{\pi}\right)$. These two parameters jointly depend on the state of the economy $S_{t}^{\pi}$. We are already assuming that exchange rate shock affects inflation with one lag, but this was also checked during estimation.

For notation reasons, we assume that regime $S_{t}^{\pi}=0$ will have the smallest volatility in aggregate supply curve shocks: $\sigma_{A S}^{2}\left(S_{t}^{\pi}=0\right)<\sigma_{A S}^{2}\left(S_{t}^{\pi}=1\right)$. The model allows for the possibility that regimes may occur recurrently through transition probabilities. There is no ex-ante restriction to a higher pass-through period occurring in states $S_{t}^{\pi}=0$ or $S_{t}^{\pi}=1$.

The representation of the model in matrix notation, with the introduction of dependent variables, is as follows:

$$
A X_{t}=B E_{t} X_{t+1}+D\left(S_{t}\right) X_{t-1}+\epsilon_{t} \quad \epsilon_{t} \sim N\left(0, \Sigma\left(S_{t}\right)\right)
$$

where matrix $D\left(S_{t}\right)$ takes a different value in each regime, and so do the variance-covariance matrices between structural shocks $\Sigma\left(S_{t}\right)$. Note that the regime shift could also occur in matrices $A$ and $B$; however, this is not necessary in our case. 
One of the advantages of the representation method adopted by Baele et al. (2015) is its simplicity. Liu and Mumtaz (2010) and Gonçalves et al. (2016), for example, follow the more complex state-space representation and solution method of Farmer et al. (2011). We follow the method proposed by Baele et al. (2015), which is based on Farmer et al. (2011) and Cho (2014), to characterise the stability and determinacy of the rational expectations equilibrium of the model. During the estimation process, described below, each maximum likelihood solution will be tested for determinacy conditions. If the model is indeterminate when evaluated at the parameters $\hat{\theta}$, then the likelihood function is heavily penalised in order to discard this point in estimation. For further details, we refer the reader to Cho (2014) or to Appendix A in Baele et al. (2015).

\subsection{Identifying the model by using survey expectations}

As previously described, our identification and estimation strategy for the MS model follows Baele et al. (2015) and makes use of observed survey-based market expectations. Survey expectations for inflation and output gap follow the law of motion below:

$$
\begin{array}{ll}
\pi_{t}^{f}=\alpha E_{t} \pi_{t+1}+(1-a) \pi_{t-1}^{f}+w_{t}^{\pi} & w_{t}^{\pi} \sim N\left(0, \sigma_{f}^{\pi}\right), \\
y_{t}^{f}=\alpha E_{t} y_{t+1}+(1-a) y_{t-1}^{f}+w_{t}^{y} & w_{t}^{y} \sim N\left(0, \sigma_{f}^{y}\right) .
\end{array}
$$

The equations allow for a slow adjustment mechanism for the formation of expectations, in which survey expectations potentially react to rational expectations one-to-one only when parameter $\alpha$ is equal to 1 . Otherwise, the adjustment of expectations is slower and depends on past values. This process is inspired by Mankiw and Reis's (2002) model of the Phillips curve, in which the information disseminates slowly.

Baele et al. (2015) simplify the estimation mechanism by assuming that the volatility of shocks $\sigma_{f}^{\pi}$ and $\sigma_{f}^{y}$ in the equations for expectations movement is equal to zero. In this case, the survey-based expectations are the exact function of current expectations and of the past values from the survey. Substituting both equations above into our main model, we have:

$$
\begin{aligned}
& \pi_{t}=\frac{\delta}{\alpha}\left(\pi_{t}^{f}-(1-\alpha) \pi_{t-1}^{f}\right)+(1-\delta) \pi_{t-1} \\
&+\lambda y_{t}+\kappa_{1 s_{t}} \Delta e_{t-1}+\epsilon_{\pi, t}, \\
& y_{t}=\frac{\mu}{\alpha}\left(y_{t}^{f}-(1-\alpha) y_{t-1}^{f}\right)+(1-\mu) y_{t-1} \\
&-\phi i_{t}+\frac{\phi}{\alpha}\left(\pi_{t}^{f}-(1-\alpha) \pi_{t-1}^{f}\right)+\epsilon_{y, t},
\end{aligned}
$$




$$
\begin{aligned}
& i_{t}=\rho_{i} i_{t-1}+\left(1-\rho_{i}\right)\left[\frac{\beta}{\alpha}\left(\pi_{t}^{f}-(1-\alpha) \pi_{t-1}^{f}\right)+\gamma y_{t}\right]+\epsilon_{i, t} \\
& \Delta e_{t}=\rho_{e} \Delta e_{t-1}+\epsilon_{e, t}
\end{aligned}
$$

where $\epsilon_{\pi, t} \sim N\left(0, \sigma_{A S}^{2}\left(S_{t}\right)\right), \epsilon_{y, t} \sim N\left(0, \sigma_{I S}^{2}\right), \epsilon_{i, t} \sim N\left(0, \sigma_{M P}^{2}\right), \epsilon_{e, t} \sim N\left(0, \sigma_{e}^{2}\right)$. Note that when $\alpha=1$, it is assumed that rational expectations are equivalent to survey expectations. Defining $X_{t}^{f}=\left[\begin{array}{ll}\pi_{t}^{f} & y_{t}^{f}\end{array}\right]^{\prime}$, we can write the model in matrix form:

$$
A X_{t}=B X_{t}^{f}+D X_{t-1}^{f}+G_{S_{t}} X_{t-1}+\epsilon_{t} \quad \epsilon_{t} \sim N\left(0, \Sigma\left(S_{t}\right)\right)
$$

where the matrices are specified as follows:

$$
\begin{aligned}
& A=\left[\begin{array}{cccc}
1 & -\lambda & 0 & 0 \\
0 & 1 & \phi & 0 \\
0 & -\left(1-\rho_{i}\right) \gamma & 1 & 0 \\
0 & 0 & 0 & 1
\end{array}\right], \quad G_{S_{t}}=\left[\begin{array}{cccc}
(1-\delta) & 0 & 0 & K_{1 S_{t}} \\
0 & (1-\mu) & 0 & 0 \\
0 & 0 & \rho_{i} & 0 \\
0 & 0 & 0 & \rho_{e}
\end{array}\right], \\
& B=\left[\begin{array}{cc}
\frac{\delta}{\alpha} & 0 \\
\frac{\phi}{\alpha} & \frac{\mu}{\alpha} \\
\frac{\left(1-\rho_{i}\right) \beta}{\alpha} & 0 \\
0 & 0
\end{array}\right], \\
& \left.\begin{array}{cccc}
-\frac{\delta(1-\alpha)}{\alpha} & 0 \\
\sigma_{A S}^{2}\left(S_{t}\right) & 0 & 0 & 0 \\
0 & \sigma_{I S}^{2} & 0 & 0 \\
0 & 0 & \sigma_{M P}^{2} & 0 \\
0 & 0 & 0 & \sigma_{e}^{2}
\end{array}\right] .
\end{aligned}
$$

If we establish the condition that $\alpha \neq 0$ and ensure the invertibility of matrix $A$, we can multiply each side of the equation by $A^{-1}$ and get the following reduced form, which will be used for the estimation:

$$
X_{t}=\Omega_{1} X_{t}^{f}+\Omega_{2} X_{t-1}^{f}+\Omega_{3}\left(S_{t}\right) X_{t-1}+\Gamma \epsilon_{t} \quad \epsilon_{t} \sim N\left(0, \Sigma\left(S_{t}\right)\right) .
$$

In this equation, we have $\Omega_{1}=A^{-1} B, \Omega_{2}=A^{-1} D, \Omega_{3}\left(S_{t}\right)=A^{-1} G_{S_{t}}$ and $\Gamma=A^{-1}$. Baele et al. (2015) highlight the advantage of this approach: the matrices that determine the law of motion of vector $X_{t}$ are simple analytical functions of the structural parameters, which makes calculation of the likelihood function relatively easy. Market expectations add new information, which is absent from the other 
variables and from the structure of the original model and which will contribute to estimation. It will not be necessary to compute the rational expectations equilibrium with multiple regimes, solving the model at each step of the likelihood optimisation, as in Farmer et al. (2011), and Liu and Mumtaz (2010). Instead, unobserved regimes will be inferred by the conventional multivariate methods proposed by Hamilton (1989) and Kim and Nelson (1999). More specifically, we will maximise the log-likelihood function of a structural VAR (SVAR) model with regime switching, in which structural restrictions stem from the new Keynesian model and are given by matrices $A, B, D, G_{S_{t}}, \Sigma\left(S_{t}\right)$. Estimation of the likelihood function of the regime-switching VAR model follows the description by Hamilton (1994), Bellone (2005), and Krolzig (1997), and the algorithm of inference about regimes is the conventional Hamilton filter, which was implemented according to Kim and Nelson (1999).

\section{Data and Estimation}

This section describes the observed data series used for estimation and the maximum likelihood method adopted.

\subsection{Descriptive statistics and stationarity tests}

Model estimation requires six observed variables: inflation, output gap, interest rate, exchange rate movement, and survey expectations for inflation and output gap. The sample used for estimation includes 64 quarterly observations, from 2000Q1 to 2015Q4. We opted to exclude the year 1999 from the sample due to the large fluctuations observed shortly after the transition to the floating exchange rate regime, and also because data on survey expectations are not readily available.

The data sources are briefly described here; more details are given in the Appendix. We use the consumer price index IPCA to measure inflation. We extract the output gap from GDP using the Hodrick-Prescott Filter. We measure the quarterly interest rate $i_{t}$ as the nominal interest rate discounted for the longrun real interest rate. In this way, we try to account for the fact that the Brazilian economy experienced a sharp reduction in its long-run real interest rate between 2005 and 2012. The data we are plugging into the model is the nominal rate in excess of the long run real rate, and we should obviously consider this when interpreting our estimation results. We measure exchange rate fluctuations from the first difference of the nominal exchange rate, BRL to USD at the end of the period. Finally, we use the Central Bank of Brazil's survey of market expectations to extract next period inflation and output gap expectations. ${ }^{2}$ Table 1 presents the descriptive statistics for the time series.

\footnotetext{
${ }^{2}$ Data on expectations observed on the first business day of the quarter is used to circumvent the problem of endogeneity between expectations and the endogenous variable.
} 
Table 1. Time series descriptive statistics (units are percentage points / 100)

\begin{tabular}{lcccccc} 
& $\boldsymbol{\pi}_{\boldsymbol{t}}$ & $\boldsymbol{y}_{\boldsymbol{t}}$ & $\boldsymbol{i}_{\boldsymbol{t}}$ & $\boldsymbol{\Delta} \boldsymbol{e}_{\boldsymbol{t}}$ & $\boldsymbol{E}_{\boldsymbol{t}} \boldsymbol{\pi}_{\boldsymbol{t + 1}}$ & $\boldsymbol{E}_{\boldsymbol{t}} \boldsymbol{y}_{\boldsymbol{t + 1}}$ \\
\hline Mean & 0.0161 & 0.0002 & 0.0161 & 0.0122 & 0.0133 & 0.0096 \\
\hline Median & 0.0145 & 0.0041 & 0.0164 & -0.0066 & 0.0126 & 0.0103 \\
\hline Maximum & 0.0551 & 0.0331 & 0.0327 & 0.3143 & 0.0305 & 0.0351 \\
\hline Minimum & 0.0012 & -0.0488 & 0.0044 & -0.1708 & 0.0083 & -0.0352 \\
\hline $\begin{array}{l}\text { Standard } \\
\text { deviation }\end{array}$ & 0.0089 & 0.0164 & 0.0063 & 0.0961 & 0.0040 & 0.0159 \\
\hline Skewness & 1.9608 & -0.9021 & 0.3704 & 0.8913 & 1.9747 & -0.5447 \\
\hline Kurtosis & 8.2738 & 3.9325 & 2.8547 & 3.9075 & 8.7659 & 2.8346 \\
\hline Jarque-Bera & 115.1797 & 10.9999 & 1.5198 & 10.6694 & 130.2482 & 3.2383 \\
\hline Probability & 0.0000 & 0.0041 & 0.4677 & 0.0048 & 0.0000 & 0.1981 \\
\hline
\end{tabular}

Source: authors' calculations

We tested the series for stationarity using the conventional Augmented DickeyFuller (ADF) test with intercept and the Phillips-Perron (PP) test. The tests reject the presence of unit root at reasonable levels for all series. The exception is the output gap expectations series. We can only reject non-stationarity when taking a slightly reduced sample, ignoring the last three quarters. The reader is referred to the Appendix for a detailed description and a possible explanation for this finding, but we conclude that the econometric estimation can proceed without restrictions. For the sake of illustration, Figure 1 displays the observed data series.

\subsection{Estimation method}

The reduced-form MS model in equation (19) will be estimated by maximum likelihood using the Hamilton filter and the likelihood function of a structural VAR model with Markov switching, following the methods described in Hamilton (1994), Kim and Nelson (1999), Bellone (2005), and Krolzig (1997). We follow the notation of Kim and Nelson (1999), where $\psi_{t-1}$ is the set of information available at $t-1$, and the observed data yield $y_{t}=\left[X_{t} X_{t}^{f}\right]^{\prime}$. The full set of parameters to be estimated is called $\theta$, a line vector that contains the structural parameters of the MS model, including the volatilities of shocks and the transition probabilities between regimes $p, q$. A total of 18 parameters must be estimated:

$$
\begin{array}{r}
\theta=\left\{\delta, \lambda, \kappa_{1 S_{t}}\left(S_{t}=0\right), \kappa_{1 S_{t}}\left(S_{t}=1\right), \mu, \phi, \rho_{i}, \beta, \gamma, \rho_{e}, \alpha, \sigma_{A S}\left(S_{t}=0\right),\right. \\
\left.\sigma_{A S}\left(S_{t}=1\right), \sigma_{I S}, \sigma_{M P}, \sigma_{e}, p, q\right\} .
\end{array}
$$

The log-likelihood function is given by $\ln L=\sum_{t=1}^{T} \ln \left(f\left(y_{t}\right)\right)$, where $f\left(y_{t}\right)$ is expressed in terms of its parameters $\theta$. The aim is to maximise the density function $\ln L\left(y_{t} ; \theta\right)$. In the case of regime-switching models, we do not observe regimes $S_{t}$, but we can infer information about them in every time period. The reader is referred to Kim and Nelson (1999) for a detailed description of the 
Figure 1. Observed data series (units are percentage points / 100)
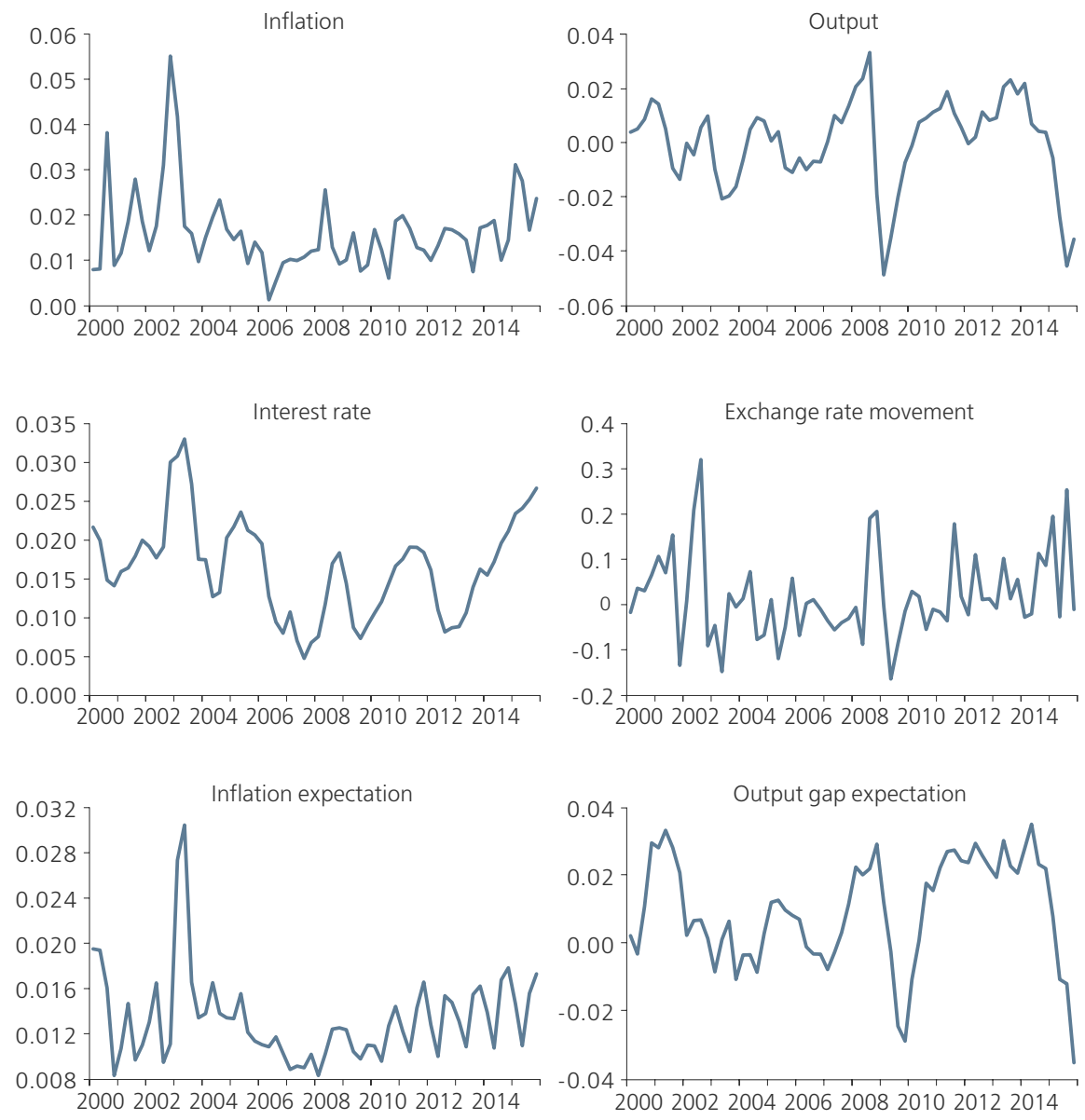

Note: time interval is from $2000 \mathrm{Q} 1$ to $2015 \mathrm{Q} 4$.

Source: authors' calculations

estimation algorithm. In what follows, we describe some of the peculiarities of our implementation.

We begin by assigning an initial value to each parameter of vector $\theta_{0}$, and proceed by maximising the log-likelihood function with a numerical constraint optimisation algorithm. The initial values were chosen based on estimation results obtained by Baele et al. (2015). The constraints are applied on the bounds of each parameter, and stem from theoretical assumptions of the structural model. Our constraints are similar to those of Baele et al. (2015), but less restrictive. Initial values and constraints are detailed in the Appendix. At each optimisation step, the parameters of the candidate vector $\theta_{i}$ are used to construct matrices $A, B, D, G_{S_{t}^{\prime}}, \Sigma\left(S_{t}\right)$, which represent the model in its structural form. We compute the model in reduced form, calculating matrices $\Omega_{1}, \Omega_{2}, \Omega_{3}\left(S_{t}\right), \Gamma\left(S_{t}\right)$. With this process complete and the candidate transition probabilities in hand, the log-likelihood calculation is carried 
out by the Hamilton filter, using the sample likelihood function of an MS-VAR model $^{3}$ (Hamilton, 1994; Bellone, 2005; Krolzig, 1997). Finally, we check whether the determinacy conditions for the rational expectations equilibrium are met with each candidate solution vector $\theta_{i}$, and we penalize the objective function if that is not the case. This procedure guarantees that the search will be made along a stable solution path.

\section{Empirical results}

In this section, we discuss the estimation results for the MS model and compare them with the conventional fixed coefficients model. Next, we analyse the impulse response functions. Finally, we interpret the regimes identified by the MS model according to economic events which occurred in the Brazilian economy, and put the model to work in an out-of-sample prediction exercise.

\subsection{Parameter estimation in the MS model}

Recall that the estimation was made using the sample period from 2000Q1 to 2015Q4. Table 2 shows the estimates for each parameter in the MS model, as well as their standard deviation and corresponding $p$-value as obtained in the conventional $t$-test. The variance-covariance matrix of the maximum likelihood estimates was calculated using the information matrix outer product method (Hamilton ,1994). The solution offered by the model characterizes a fundamental stable rational expectations equilibrium, as discussed above.

Most parameters are statistically significant. Recall that the signs of the parameters are guaranteed by the constraints imposed on the likelihood function optimisation and that no parameter was calibrated. The parameters for which joint regime switching was allowed were the pass-through coefficient $\kappa_{1 S_{t}}$ and the volatility of shocks $\sigma_{A S}\left(S_{t}^{\pi}\right)$ to inflation.

In the aggregate supply (AS) equation of the MS model we estimated $\delta=0.6971$, demonstrating a relatively heavier weight to inflation expectations in comparison with the endogenous persistence (backward-looking) term. This value is quite close to the estimates made by da Silveira (2008), who found $\delta=0.61$ in a price indexation model. In the demand curve (IS), however, a smaller weight was estimated to the expected output gap component, $\mu=0.1234$. This fact suggests either higher output persistence, or lower predictive power of market expectations about future output. Da Silveira (2008) found parameters that would correspond to $\mu=0.26$, and a confidence interval that would include our value of $\mu=0.12$. By and large, we consider that the model provides evidence in favour of the endogenous persistence of both output and inflation.

\footnotetext{
${ }^{3}$ Details about the likelihood function are also available in the Appendix.
} 
Table 2. Parameters estimated for the MS model

\begin{tabular}{|c|c|c|c|c|}
\hline \multicolumn{5}{|c|}{ 1. Parameters for the inflation curve } \\
\hline$\delta$ & $\lambda$ & $\kappa_{1 S_{t}}\left(S_{t}^{\pi}=0\right)$ & \multicolumn{2}{|l|}{$\kappa_{1 S_{t}}\left(S_{t}^{\pi}=1\right)$} \\
\hline 0.6971 & 0.0722 & 0.0004 & \multicolumn{2}{|l|}{0.0722} \\
\hline $0.1189(0.000)$ & $0.0508(0.145)$ & $0.0153(0.397)$ & \multicolumn{2}{|l|}{$0.0316(0.026)$} \\
\hline \multicolumn{5}{|c|}{ 2. Parameters for the output gap curve } \\
\hline$\mu$ & \multicolumn{4}{|l|}{$\phi$} \\
\hline 0.1234 & \multicolumn{4}{|l|}{0.6740} \\
\hline $0.1056(0.199)$ & \multicolumn{4}{|l|}{$0.3043(0.037)$} \\
\hline \multicolumn{5}{|c|}{ 3. Monetary policy parameters } \\
\hline$\rho_{i}$ & $\beta$ & \multicolumn{3}{|l|}{$\gamma$} \\
\hline 0.2515 & 0.7852 & \multicolumn{3}{|l|}{0.0117} \\
\hline $0.0711(0.001)$ & $0.1692(0.000)$ & \multicolumn{3}{|l|}{$0.0680(0.390)$} \\
\hline \multicolumn{3}{|c|}{ 4. Parameters for exchange rate dynamics } & \multicolumn{2}{|c|}{ 5. Expectations formation } \\
\hline \multicolumn{3}{|l|}{$\rho_{e}$} & \multicolumn{2}{|l|}{$\alpha$} \\
\hline \multicolumn{3}{|l|}{0.1488} & \multicolumn{2}{|l|}{0.9999} \\
\hline \multicolumn{3}{|l|}{$0.1685(0.267)$} & \multicolumn{2}{|l|}{$0.2583(0.000)$} \\
\hline \multicolumn{5}{|l|}{ 6. Volatilities } \\
\hline$\sigma_{A S}\left(S_{t}^{\pi}=0\right)$ & $\sigma_{A S}\left(S_{t}^{\pi}=1\right)$ & $\sigma_{I S}$ & $\sigma_{M P}$ & $\sigma_{e}$ \\
\hline 0.0043 & 0.0096 & 0.0108 & 0.0043 & 0.0950 \\
\hline $0.0024(0.002)$ & $0.0063(0.028)$ & $0.0040(0.000)$ & $0.0023(0.001)$ & $0.0425(0.000)$ \\
\hline \multicolumn{5}{|c|}{ 7. Transition probabilities } \\
\hline$q$ & \multicolumn{4}{|l|}{$p$} \\
\hline 0.9583 & \multicolumn{4}{|l|}{0.9559} \\
\hline $0.0608(0.000)$ & \multicolumn{4}{|l|}{$0.0412(0.000)$} \\
\hline \multicolumn{5}{|l|}{ 8. Statistics } \\
\hline$R_{A S}^{2}$ & $R_{I S}^{2}$ & $R_{M P}^{2}$ & $R_{e}^{2}$ & Log-likelihood \\
\hline 0.4728 & 0.5112 & 0.5384 & 0.0063 & 752.0262 \\
\hline
\end{tabular}

Note: the first row contains the parameter estimation; the second row contains the standard deviation and $p$-values in brackets. Sample period for estimation: 2000Q1 to 2015Q4.

Source: authors' calculations

The response of inflation to the output gap is estimated at $\lambda=0.0722$, which is in line with Bayesian estimations of more complex new Keynesian models such as Gonçalves et al. (2016) who obtain $\lambda=0.0654$. Our result, however, is not statistically significant. In fact, several studies on the Phillips curve for the Brazilian economy do not demonstrate a statistically significant effect on inflation from the output gap, or from marginal cost (Alves and Areosa, 2005; Areosa and Medeiros, 2007; Arruda et al., 2011), prompting Sachsida (2013) to question the validity of this assumption. An exception is Mazali and Divino (2010), who use GMM estimation. We tested for alternative measures of the output gap, such as the Beveridge-Nelson decomposition suggested by Tristão and Torrent (2015), but none of them resulted in improvements. In any case, further investigation into this topic is not within the scope of this paper.

The MS model identifies two distinct regimes regarding the behaviour of exchange rate pass-through, confirming the major assumption of our paper. 
We refer to the regimes as $S_{t}=0$ and $S_{t}=1$, which correspond to low and high exchange rate pass-through periods, respectively. The value estimated in the AS curve for the pass-through in regime $S_{t}=0$ is statistically zero, with $\kappa_{1 S_{t}}\left(S_{t}=0\right)=0.0004$. The point estimate would correspond to a long-run effect of only 0.00057 of a percentage point on inflation, which is practically zero, considering a $1 \%$ exchange rate shock (depreciation of the domestic currency). On the other hand, the estimate for regime $S_{t}=1$ is $\kappa_{1 S_{t}}\left(S_{t}=1\right)=0.0722$, with strong statistical significance. The long-run effect, given a $1 \%$ exchange rate shock during the high pass-through regime, is 0.1035 of a percentage point on inflation. Note that the point estimate, under regime $S_{t}=1$, for the exchange rate pass-through is $10.35 \%$, an order of magnitude higher than $0.057 \%$ under the alternative regime.

In addition to a smaller pass-through regime, $S_{t}=0$ demonstrated smaller volatility in shocks to inflation, with a standard deviation estimated at $\sigma_{A S}\left(S_{t}^{\pi}=0\right)=0.0043$, compared to $\sigma_{A S}\left(S_{t}^{\pi}=1\right)=0.0096$. The transition probabilities reveal relatively high and very similar persistence for both regimes. Consequently, the economy is expected to remain in a certain regime for several quarters, once the transition occurs. Parameter $q=0.9583$ corresponds to the probability of the economy remaining in regime $S_{t}=0$ when it is already in it, i.e., $\operatorname{Pr}\left[S_{t}=0 \mid S_{t-1}=0\right]$. Additionally, parameter $p=0.9559$ is equivalent to the probability of remaining in regime $S_{t}=1$, that is $\operatorname{Pr}\left[S_{t}=1 \mid S_{t-1}=1\right]$. In brief, the model estimates that periods of high pass-through and high volatility in shocks will be slightly shorter than periods of low pass-through and low volatility. For the sake of simplicity, we will, henceforth, refer to regime $S_{t}=1$ as 'crisis' and to regime $S_{t}=0$ as 'normal'.

The MS model is superior to the fixed parameters model in terms of its better fit (parameter $R_{A S}^{2}$ ), larger log-likelihood value, and higher value for the Schwartz criterion. Table 3 gives a comparison of the models, as suggested by Hamilton (2005). ${ }^{4}$ Moreover, by assuming regime switching in the volatility of shocks, we ran the Wald test on constraint $\kappa_{1 S_{t=0}}\left(S_{t}=0\right)=\kappa_{1 S_{t}}\left(S_{t}=1\right)$. The result is rejection at $5 \%$ significance. In other words, the test rejects the hypothesis of equal pass-through coefficients in both regimes. This results strengthens our argument for the superiority of a Markov switching representation.

Table 3. Comparison between selected models

\begin{tabular}{l|c|c|c}
\multicolumn{1}{c}{ Model } & Number of parameters & Log-likelihood & Schwartz criterion \\
\hline MS & 18 & 752.03 & 714.59 \\
\hline Linear (fixed parameters) & 14 & 741.42 & 712.31 \\
\hline
\end{tabular}

Note: Schwartz criterion is calculated as $\mathcal{L}-(k / 2) \log T$, where $\mathcal{L}$ is the $\log$-likelihood, $k$ is the number of parameters and $T$ is the sample size (Hamilton, 2005).

Source: authors' calculations

\footnotetext{
${ }^{4}$ We recognise that the difference in the Schwartz criterion is not large enough for a definitive choice between the two models. The use of alternative model comparison techniques, such as Bayesian model selection is suggested for future research.
} 
The values estimated for exchange rate pass-through are consistent with earlier findings for the Brazilian economy, although the difference across sample periods does not permit strict comparisons. In particular, numerous studies include the first stage of the Real Plan (1994-1999), prior to the implementation of the inflation-targeting and floating exchange rate regime. In that initial phase, the Brazilian foreign exchange rate was highly controlled by the Central Bank, working as an anchor to prices while most of the macroeconomic shocks were absorbed by sudden shift of the interest rate.

Pimentel et al. (2016) estimate exchange rate pass-through between 1999 and 2013 assuming an asymmetric effect during appreciations as opposed depreciations. Our estimate of $10.35 \%$ for the pass-through during the 'crisis' regime is close to their estimate of the pass-through during depreciation events, which is $11.38 \%$. Correa and Minella (2010) investigated the pass-through between 1995 and 2005 , having estimated an effect of $20 \%$ on inflation for large depreciation events. Conversely, the pass-through is statistically zero for periods with small shifts in exchange rate. Our findings are comparable to those of Correa and Minella (2010), but the considerable difference between sample periods must be taken into account. Carneiro et al. (2004) analysed the period from 1994 to 2001 and found a nonlinear short-run pass-through effect ranging from $5.6 \%$ to $11 \%$, comparable to our high pass-through period estimates. Tombini and Alves (2006) presented a variable estimate for exchange rate pass-through between 2002 and 2006, which varied from zero to approximately $8 \%$, which is again consistent with our findings. Finally, our results are in line with the exchange rate pass-through estimate published by the Central Bank of Brazil (Banco Central do Brasil, 2015) in its several small-scale linear projection models.

Note that our long-run pass-through estimate of $10.35 \%$ is considered relatively low even in a 'crisis' period by the criteria established by Goldfajn and Werlang (2000) and Belaisch (2003), which implies that the economy has exhibited a reasonable capacity to absorb exchange rate shocks without direct pass-through to consumer inflation.

In order to analyse the results of the estimation for the aggregate demand (IS) and monetary policy (MP) curves we should recall that our measure of the interest rate $i_{t}$ is calculated as the nominal interest rate discounted for the long-term real interest rate. In other words $i_{t}$ is the interest rate 'in excess' of the long-term real rate. With that in mind, we find that the IS curve demonstrates a strong response by output to the interest rate 'in excess', with parameter $\phi=0.64740$. Our estimated parameter is much higher than the calibration of Baele et al. (2015), of $\phi=0.1$, or the estimation of Gonçalves et al. (2016) who obtain $\phi=0.4063$, as both of these works use only the nominal interest rate as input to their models. Our findings indicate that aggregate demand reacts strongly to the interest rate 'in excess' of the long-term real rate, which, in turn, suggests an efficient channel for monetary policy transmission in Brazil. 
Regarding the monetary policy rule, we obtain an interest rate smoothing value of $\rho_{i}=0.2515$, which is relatively small in comparison to Bayesian estimations of new Keynesian models such as Furlani et al. (2010). Again, the difference in our interest rate input series could explain a much smaller smoothing coefficient. The Central Bank would be aiming to smooth the nominal interest rate, which leads to a smaller smoothing of the interest rate that is in excess' of the long-term real rate. Parameter $\beta$, which stands for the response of the interest rate to inflation expectations, was estimated at 0.7852 and indicates an activist response to inflation. ${ }^{5}$ The interpretation that suggest itself, in our case, is that the Central Bank would be willing to raise the interest rate above the long-term real rate for every positive shock in inflation expectations.

The response of monetary policy to output is estimated at $\gamma=0.0117$, and is not statistically different from zero. A positive value indicates that the Central Bank responds to output gap deviation. Our estimate is smaller than those of Palma and Portugal (2014) and Gonçalves et al. (2016) possibly due to differences in the time series used to measure interest rates.

The exchange rate dynamics shows some positive autocorrelation in exchange rate movements, with $\rho_{e}=0.1488$, but this is not significant. The volatility of shocks to the exchange rate equation is by far the largest, and the fit of the curve is almost irrelevant.

Parameter $\alpha$ describes the law of motion of market expectations, and is very close to 1 , implying that the model disregards market expectations assessed in the previous period. According to Baele et al. (2015), this finding indicates that market expectations fully adjust to rational expectations, and the slow dissemination of information does not appear to be important in this process.

Table 4 shows the estimation results for the new Keynesian model without regime switching, for the sake of comparison. The exchange rate pass-through coefficient, estimated in the AS curve, is $\kappa_{1}=0.0419$, which corresponds to

5 It is worth noting that, if the nominal interest rate were used as the observed variable, instead of the rate 'in excess' of the long term real rate, the activist regime would be characterized by $\beta>1$. To formalise it, let our measurement of the interest rate used in the estimation be $\tilde{l}_{t}=i_{-}$nominal $-r_{-}$long_run $_{t}$. Assuming, for simplicity, that $\rho_{i}=0$, then the Taylor rule we are estimating is $\tilde{I}_{t}=\beta E_{t} \pi_{t+1}+\gamma y_{t}+\varepsilon_{i, t}$. From the Fisher equation we have the relationship between the nominal interest rate and the ex-ante real rate $i_{-}$nominal $l_{t}=r_{-}$exante $e_{t}+E_{t} \pi_{t+1}$. Substituting the two equations in the Taylor rule we obtain $r_{-}$exante $t_{t}+E_{t} \pi_{t+1}-r_{-}$long_run $_{t}=\beta E_{t} \pi_{t+1}+\gamma y_{t}+\varepsilon_{i, t}$.

Our measurement of $r_{-}$long_run $_{t}$, as defined by the measuring method, reacts to shocks to inflation expectations at $t$. We assume for simplicity that this reaction is linear, and thus the evolution of the long run rate can be written as $r_{-}$long_run $_{t}=\varphi_{l r, 1} r_{-}$long_run $_{t-1}+\varphi_{l r, 2} E_{t} \pi_{t+1}+v_{t}$. Substituting the last equation in the Taylor rule we have: $r_{-}$exante ${ }_{t}+E_{t} \pi_{t+1}-\left(\varphi_{l r, 1} r_{-} \operatorname{long}_{-} r u n_{t-1}+\varphi_{l r, 2} E_{t} \pi_{t+1}+v_{t}\right)$ $=\beta E_{t} \pi_{t+1}+\gamma y_{t}+\varepsilon_{i, t}$, which simplifies to: $r_{-}$exante $t_{t}=\left(\beta+\varphi_{l r, 2}-1\right) E_{t} \pi_{t+1}+\gamma y_{t}+\varphi_{l r, 1} r_{-}$long $_{-} r u n_{t-1}+\varepsilon_{i, t}+v_{t}$.

So, as long as the estimated values for $\beta$ and $\varphi_{l r, 2}$ sum to more than 1 , the ex-ante real rate will rise in response to a positive shock in inflation expectations, leading to stabilization of inflation via the lower output gap implied by the Euler equation. We have estimated $\hat{\varphi}_{l r, 2}=0.5883$, with standard deviation of (0.2512), using the equation of the evolution of the long run rate. The estimated value for the sum of the coefficients is $\hat{\beta}+\hat{\varphi}_{l r, 2}=1.3735$. In any case, it is worth remembering that the system has been tested for determinacy at each step of the estimation procedure, using Cho's (2014) method, as described in Section 2.2. 
a long-run effect on inflation of $7.62 \%$. Naturally, this value is somewhere between the smallest and largest pass-through values estimated in the tworegime model. The other AS curve parameters have similar values to those obtained for the MS model.

Table 4. Parameters estimated for the model without regime switching

1. Parameters for the inflation curve

\begin{tabular}{lll}
\hline$\delta$ & $\lambda$ & $\kappa_{1}$ \\
\hline 0.5497 & 0.0887 & 0.0419 \\
\hline $0.1029(0.000)$ & $0.0776(0.206)$ & $0.0158(0.014)$
\end{tabular}

2. Parameters for the output gap curve

$\mu \quad \phi$

$0.1231 \quad 0.6718$

$0.1015(0.189) \quad 0.3167(0.044)$

3. Monetary policy parameters

$\begin{array}{lll}\rho_{i} & \beta & \gamma\end{array}$

\begin{tabular}{lll}
\hline 0.2513 & 0.7857 & 0.0110 \\
\hline $0.0711(0.001)$ & $0.1614(0.000)$ & $0.0541(0.389)$
\end{tabular}

4. Exchange rate dynamics parameters 5. Expectations formation

$\rho_{e}$ 0.1488 $\alpha$

$0.1556(0.250)$ $0.2819(0.001)$

6. Volatilities

\begin{tabular}{lllll}
$\sigma_{A S}$ & $\sigma_{I S}$ & $\sigma_{M P}$ & $\sigma_{e}$ & \\
\hline 0.0073 & 0.0108 & 0.0043 & 0.0950 & \\
\hline $0.0000(0.000)$ & $0.0000(0.000)$ & $0.0000(0.003)$ & $0.0017(0.000)$ & \\
7. Statistics & & & & Log-likelihood \\
\hline$R_{A S}^{2}$ & $R_{I S}^{2}$ & $R_{M P}^{2}$ & $R_{e}^{2}$ & 741.4227 \\
\hline 0.2688 & 0.5111 & 0.5383 & 0.0063 &
\end{tabular}

Note: the first row contains the parameter estimation and the second row contains the standard deviation and $p$-values in brackets. Sample period for estimation: 2000Q1 to 2015Q4.

Source: authors' calculations

We ran several specification tests on the residuals of each equation - serial autocorrelation, normality, and conditional variance. Serial autocorrelation was rejected in general, but not in the interest rate equation. We also submitted the MS model to the Di Sanzo (2009) linearity test, which is based on a bootstrap distribution of the likelihood ratio, but could not reject the null hypothesis of linearity. Full details of the specification and linearity tests are given in the Appendix.

\subsection{Impulse response functions}

The effect of independent structural shocks on endogenous variables is represented by the impulse response functions in Figure 2. 
Figure 2. Impulse response functions for inflation, output, interest rate, and exchange rate shocks (units are percentage points / 100)

Inflation shock
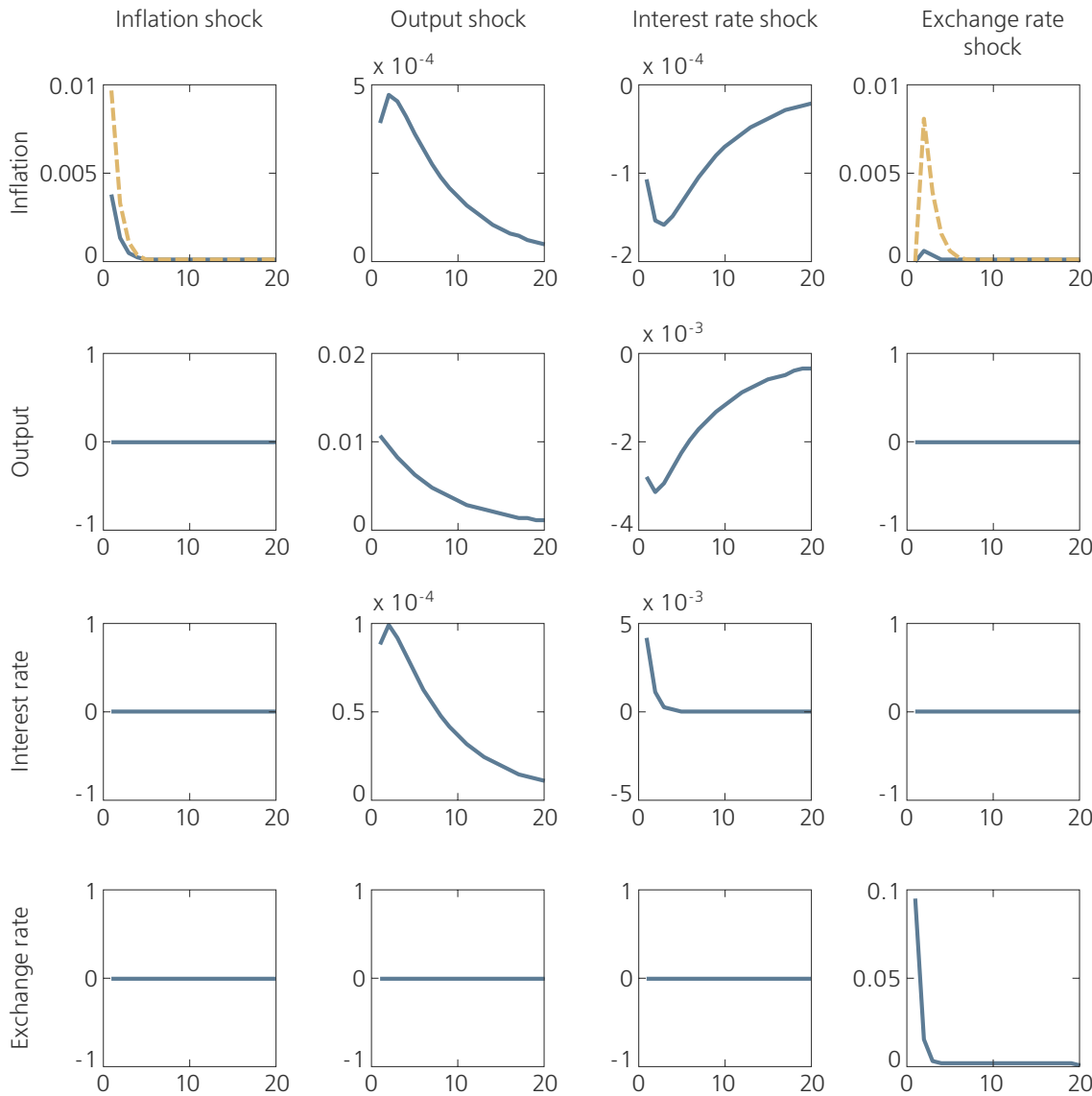

the response in regime $S_{t}=0$ ('normal')

--- the response in regime $S_{t}^{t}=1$ ('crisis')

Note: shocks represent one standard deviation.

Source: authors' calculations

The responses are, in general, consistent with standard new Keynesian models. An unexpected shock to inflation does not cause a reaction in other variables, as it is assumed that both output and interest rate should react only to inflation expectations. A shock to the output gap causes a rise in inflation and a monetary policy response. There is high persistence, with an effect on the steady state even after 20 quarters. In turn, the unexpected shock to the interest rate reduces output and inflation.

Regime switching affects the response of inflation given supply shocks and shocks to the exchange rate. A typical supply shock has stronger relative effects during the 'crisis' period simply because of the higher estimated standard 
deviation. Regarding the exchange rate shock, the magnitude of the pass-through is much larger in the 'crisis' regime, so the effect on inflation is stronger and lasts for approximately twice as long. The behaviour of each variable was calculated by assuming no regime switching after the shock.

\subsection{Identification of high exchange rate pass-through regimes}

One of the key results of the MS model is the identification of macroeconomic regimes, which, in our case, correspond either to the 'normal' regime (low exchange rate pass-through and lower volatility of shocks to inflation) or the 'crisis' regime (high exchange rate pass-through and increased volatility of shocks to inflation).

As previously commented, both regimes demonstrate strong persistence, with a slightly higher value attributed to the 'normal' regime. In effect, the expected duration for the 'normal' cycle is $E\left(D \mid S_{t}=0\right)=24.0$ quarters against $E\left(D \mid S_{t}=1\right)=22.7$ quarters for the 'crisis' cycle.

The graphs in Figure 3 show filtered and smoothed probabilities for each regime throughout the period 2000 to 2015 . Note that the probabilities tend to be concentrated around one or zero most of the time, allowing for a plausible identification of regimes and confirming the usefulness of the model. We are able to clearly identify two periods of high exchange rate pass-through and high volatility of shocks to inflation, with a duration between six and fourteen quarters. Table 5 summarises the information on the beginning and end of each period, as well as on exchange rate movements and accumulated inflation. The 'crisis' regime totals 20 quarters, whereas the 'normal' regime extends for 44 consecutive quarters.

Table 5. Periods of high exchange rate pass-through and high volatility of shocks to inflation identified by the MS model

\begin{tabular}{c|c|c|c|c|c|} 
Beginning & End & $\begin{array}{c}\text { Duration } \\
\text { (quarters) }\end{array}$ & Identification & $\begin{array}{c}\text { Larger exchange rate } \\
\text { depreciation } \\
\text { (in one quarter) }\end{array}$ & $\begin{array}{c}\text { Inflation accumulated } \\
\text { in the period (IPCA) }\end{array}$ \\
\hline $2000 \mathrm{Q} 1$ & $2003 \mathrm{Q} 2$ & 14 & $\begin{array}{c}\text { Internet bubble } \\
\text { (USA) and domestic } \\
\text { electoral crisis }\end{array}$ & $31.4 \%$ & $36.3 \%$ \\
\hline $2014 \mathrm{Q} 3$ & $2015 \mathrm{Q} 4$ & 6 & $\begin{array}{c}\text { Domestic political } \\
\text { crisis }\end{array}$ & $24.7 \%$ & $12.9 \%$ \\
\hline
\end{tabular}

Source: authors' calculations

During each cycle of the 'crisis' regime, we find large exchange rate depreciations, between $24.7 \%$ and $31.4 \%$, in at least one of the quarters. Exchange rate shocks above certain limits are one of the arguments presented by Correa and Minella (2010) for the nonlinear behaviour of exchange rate pass-through, and this feature appears to be relevant here. Note that mean exchange rate depreciation per quarter in 'crisis' regimes is as high as $5.22 \%$ against a mean appreciation of $0.6 \%$ in 'normal' regimes. Taking the whole sample, we observe a mean depreciation of $1.2 \%$ per quarter. However, we identified some quarters in which large exchange 
rate depreciations (above 10\%) were not enough to characterise a 'crisis' regime in the pass-through. In other words, in a few cases, the economy appears to be able to absorb exchange rate shock without significant pass-through to inflation. Take for example quarters 2011Q3 and 2012Q2, which had exchange rate depreciations of $17.2 \%$ and $10.3 \%$, respectively. Mean inflation per quarter during the 'crisis' regime was $2.19 \%$, a much higher value than the overall sample mean of $1.60 \%$, or the 'normal' regime mean of $1.34 \%$. Note that quarterly inflation exceeded $2 \%$ in only one occasion (2004Q3) out of 44 in which the 'normal' regime was active.

Figure 3. Probabilities estimated for the MS model
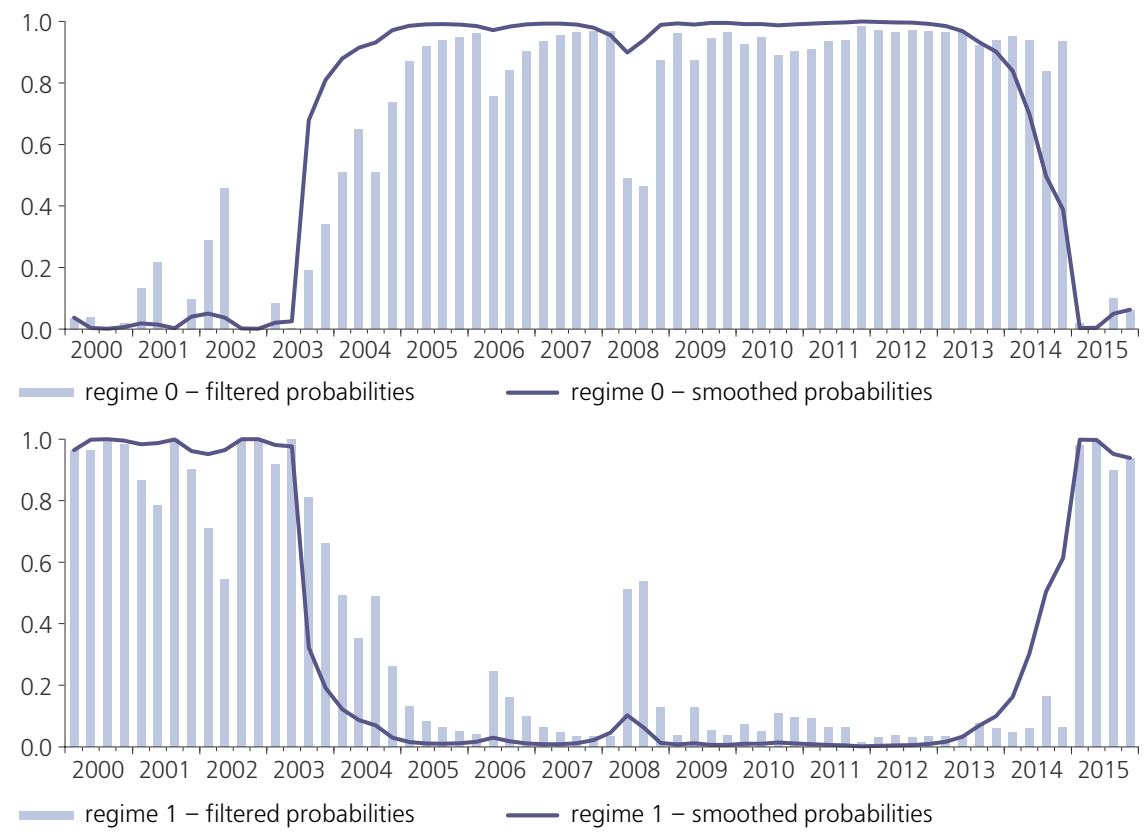

Note: sample period: 2000Q1 to 2015Q4.

Source: authors' calculations

The first 'crisis' cycle begins in 2000Q1 and lasts until mid-2003. The period is characterised by several events that affected confidence in the Brazilian economy. First, the transition to the floating exchange rate regime and the resulting sharp exchange rate depreciation of 1999 resulted in a sudden increase in inflation for the following quarters. What's more, the bursting of the US stock market bubble for high-tech companies in 2000 triggered considerable uncertainty in international financial markets. Emerging market economies such as Brazil suffered capital outflows, exchange rate depreciations, and an increased country risk premium. In addition, the political crisis in neighbouring Argentina, a major trade partner, was particularly severe in 2000-2001. To make things worse, the Brazilian 
economy was hit by a systemic shortage of energy between 2001 and 2002 which forced the government to establish ceilings on energy consumption. The ceilings forced a reduction of energy use by up to $20 \%$ in some regions. All this had an effect on the perception of country risk in Brazil. For instance, in the third quarter of 2000, Brazilian exchange rate depreciation amounted to $8.42 \%$, with a peak in inflation of $3.82 \%$. In 2001Q3, we observe another significant exchange rate shock with a further increase in the country risk premium. ${ }^{6}$

Over the year 2002, the Brazilian presidential elections marked another severe confidence crisis. Markets were sceptical about the economic policy intentions of the Labour party's presidential candidate, who was pulling far ahead in the opinion polls. The country risk premium increased considerably, reaching its peak in October 2002.7 The domestic currency experienced more than $50 \%$ depreciation in 2002 , while yearly inflation exceeded $12 \%$. Indeed, inflation volatility only decreased at the end of 2003, as the new government consolidated its' monetary and economic policies, which turned out to be orthodox and in accordance with the principles of inflation-targeting.

The following period, a long 'normal' cycle, starts in mid-2003 and lasts until the end of 2014, totalling 44 consecutive quarters. Note that the exchange rate had quite a significant appreciation from the beginning to the end of the period, 32\% from 2003Q2 to 2014Q2, although we observe a few quarters with depreciations higher than $10 \%$.

The fact that exchange rate pass-through is low in that period is consistent with the findings of Pimentel et al. (2016) concerning the asymmetric effect of exchange rate movements. According to their study, appreciations tend to exhibit a much lower pass-through level than depreciations of the same size. The total appreciation of $32 \%$ contributed to keeping inflation low during this period. An intriguing question is why depreciations greater than $10 \%$ in some quarters did not trigger a higher level of pass-through. For example, in the second and third quarters of 2008, during the onset of the international financial crisis, the MS model indicates an increase in the probability of a 'crisis' cycle. Exchange rate depreciation reaches 42\% between 2008Q3 and 2008Q4, even though inflation is kept at relatively low levels for both 2008 and the following year. As a result, the smoothed probabilities signal that the economy appears to remain in a 'normal' cycle. Thus, according to the model, sharp depreciation was not enough to substantially raise the level of passthrough. This finding contradicts Correa and Minella's (2010) threshold explanation. In our opinion, there are two possible reasons for this phenomenon. First, the sudden negative shock in economic activity during 2008-2009 could be helping to alleviate inflation pressures, in line with the assumptions of Phillips curve. Secondly, confidence appears to play a certain role. The 'crisis' cycle is being signalled by the

\footnotetext{
${ }^{6}$ The Embi+BR country risk premium index, measured by JP Morgan, had an average monthly value of 1,165 basis points in October 2001 .

${ }^{7}$ The Embi+BR index had an average monthly value of 2,039 basis points in October 2002.
} 
model during phases when the Brazilian economy appears to be in distress, as was the case from 2000-2003 and during the final cycle (2015) described below. The events of 2008-2009 crisis originated in foreign economies and did not specifically affect confidence in the foundations of the Brazilian economy or confidence in the inflation targeting regime.

From the beginning of 2015, the MS model begins to clearly indicate a new 'crisis' cycle. We see a strong exchange rate depreciation (18.9\%) in 2015Q1 and a consistent rise in inflation levels. The period is characterised by a severe downturn in economic activity in Brazil, political crisis at the federal government level, and fiscal hardships. In fact, the high persistence of inflation combined with an expansionary and unsustainable government budget has tied the hands of the monetary authority. Based on the findings of the model, one would expect that the $24.7 \%$ exchange rate shock of 2015Q3 would have a substantial effect on inflation during the following quarters.

\subsection{Putting the model to work: analysing pass-through from 2016Q1 to 2018Q2}

In order to test the MS model, we have predicted the probabilities of each regime for the out-of-sample period, from 2016Q1 to 2018Q2, using the model parameters previously estimated. In this exercise, at each point $t$ in time, we feed the data series observed until $t$ and calculate the implied probabilities for the 'crisis' and 'normal' regime of exchange rate pass-through. ${ }^{8}$ The results are shown in Figure 4.

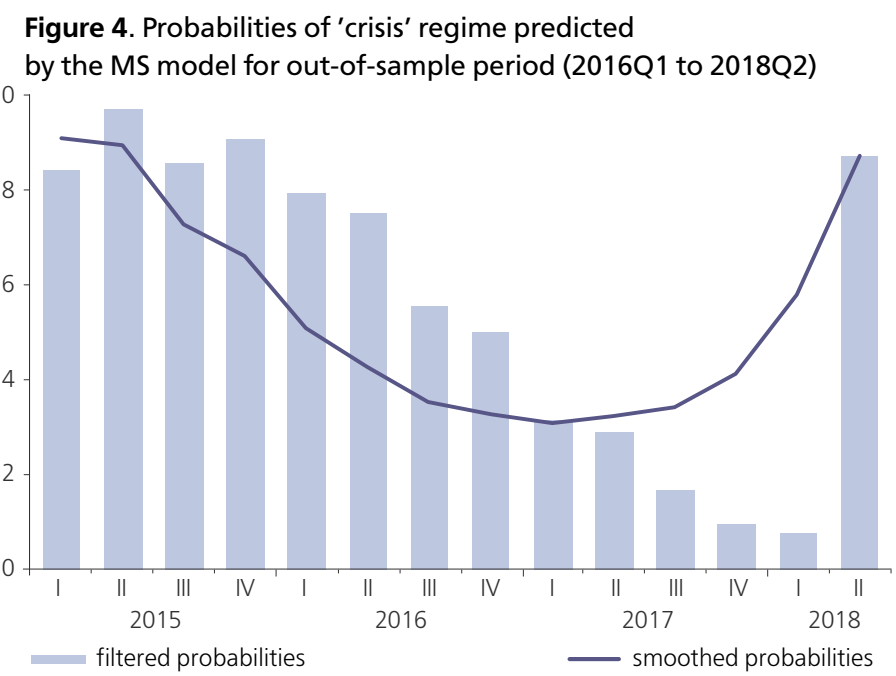

Source: authors' calculations

\footnotetext{
${ }^{8}$ The exercise is considered out-of-sample in the sense that we do not re-estimate the model at each step, but rather use the point estimates obtained before.
} 
As mentioned above, 2015 is characterised by a profound downturn in economic activity in Brazil, political crisis at the federal government level, and fiscal hardship. The high persistence of inflation is fuelled by expansionary fiscal policy, and a delayed response by the monetary authority to inflation. The model is in a 'crisis' cycle which began in 2015Q1.

The out-of-sample prediction gives us new and informative results. The crisis cycle lasts for seven quarters, 2016Q3, according to the filtered probabilities. This date coincides with a change in the board of directors of the Central Bank of Brazil, as the new president took office in August 2016. Starting from the beginning of 2017 the model indicates a higher probability for a new normal cycle, which lasts until the second quarter of 2018, almost the end of our sample. This evidence points to a possible role for the credibility of the monetary authority in moderating the effect of pass-through. A central bank that is more credible in terms of its willingness to react to inflation will be able to adjust agents' expectations to a lower level of inflation, for the same exchange rate shock. In other words, when inflation expectations are well-anchored, firms will tend to moderate the extent to which they engage in repricing, and exchange rate pass-through will be lower. Indeed, both inflation expectations and observed consumer price inflation drop sharply from the end of 2016 until more or less the beginning of 2018. We see evidence that the new board was able to better anchor inflation expectations and thus achieve a lower pass-through.

Our finding is in line with recent research relating central bank credibility to a variable degree of exchange rate pass-through. De Mendonça and Tiberto (2017) measure central bank credibility using panel data including 114 developing countries to establish that credibility can counteract the effects of exchange rate depreciations on inflation. They argue that monetary authorities committed to anchoring inflation expectations can obtain increased credibility that helps to reduce exchange rate pass-through. In a study focusing on the Brazilian economy, Montes and Ferreira (2018) find that central bank credibility is capable of mitigating the spread of uncertainties about the exchange rate to uncertainties about the inflation and interest rates. This channel, of uncertainty reduction, could also be beneficial in reducing the degree of repricing by firms whenever the economy is subject to an exchange rate shock.

A note must be made regarding the last period of the out-of-sample prediction. The model points to a high probability of the 'crisis' cycle returning during 2018Q2. In fact, the exchange rate has suffered a sharp depreciation, over $20 \%$ from 2017Q4 to 2018Q2 and observed consumer price inflation turned out to be unexpectedly high in 2018Q2. We consider two alternative hypotheses to explain this spike. The first is related to a domestic supply shock. Huge disruption was caused to the domestic supply chain in Brazil when truck drivers across the country went on strike, and the prices of food and other basic items suddenly increased. The second, alternative, explanation is that the Brazilian economy may 
have experienced a return to the 'crisis' cycle of high pass-through. In any case, the sustained credibility of the central bank may allow the economy to either remain in or return to a low pass-through 'normal' cycle, especially if this is combined with a positive shock to fundamentals in the near term.

\section{Conclusion}

This paper investigates exchange rate pass-through in the Brazilian economy during the floating exchange rate period using a structural new Keynesian MS model. Our basic hypothesis is of nonlinear behavior in the pass-through coefficient, combined with regime switching in the volatility of shocks to the aggregate supply curve.

Our empirical results show that the exchange rate pass-through assumed two possible states, or regimes, during the years 2000 to 2015. In the first regime, referred to for convenience as 'normal', the pass-through is very low and statistically nonsignificant while, at the same time, the volatility of shocks to inflation is also relatively low. In the second regime, the pass-through (about $10.3 \%$ in the long run) is relevant and significant, while the volatility of shocks to inflation is also relatively higher. The high pass-through regime is referred as 'crisis' as it appears to occur in periods when the Brazilian economy is facing various types of distress, or else a confidence crisis. The MS model outperformed the linear specification according to some of the usual econometric criteria, such as the Schwartz criterion.

Our estimates for the nonlinear exchange rate pass-through in the Brazilian economy are consistent with those obtained by Carneiro et al. (2004), Correa and Minella (2010), and Pimentel et al. (2016), taking into account differences between the periods of interest and the estimation method. It should be highlighted that the long-run pass-through of $10.3 \%$ even in the 'crisis' regime is relatively low according to the criteria set by Goldfajn and Werlang (2000), and Belaisch (2003), which implies that the economy has a reasonable capacity to absorb exchange rate shocks without exerting a greater impact on consumer inflation.

The presence of regime switching in the volatility of shocks to inflation could be related to the heteroskedasticity of inflation itself (Engle, 1982; Brunner and Hess, 1993) or to theoretical arguments, such as Ball and Cecchetti's (1990) and Owyang's (2001). These authors point out that higher inflation levels lead to higher volatility and greater uncertainty over future inflation expectations. That is, unexpected inflation shocks increase uncertainty over future inflation and cause increased volatility in inflation in the subsequent periods. The system would tend to remain in a high volatility regime for a number of periods, which is well described in our findings.

This study innovates in terms of methodology by using a Markov Switching DSGE model to identify nonlinear exchange rate pass-through in an emerging 
economy. In the case of Brazil, previous studies usually sought to measure exchange rate pass-through directly in the Phillips curve (Carneiro et al., 2004; Correa and Minella, 2010; Nogueira Jr, 2010; Pimentel et al., 2016) or in regressions specifically derived from microfoundations, such as in Albuquerque and Portugal (2005). As econometric methods, the literature employs nonlinear least squares (Carneiro et al., 2004), threshold models (Correa and Minella, 2010), smooth transition regression (Nogueira Jr, 2010), asymmetric SVAR models (Pimentel, et al., 2016), linear state-space models with variable parameters (Albuquerque and Portugal, 2005), or univariate Markov switching regressions on the Phillips curve (Baharumshah et al., 2017). Our review of the extant literature did not find previous publications using Markov switching DSGE models to assess exchange rate pass-through in emerging or advanced economies. Our work also differs from that of Baele et al. (2015) in that they are focused on regime changes in monetary policy.

We make a novel contribution by identifying four phases, or cycles, for passthrough behaviour in the Brazilian economy during the inflation targeting period. In our interpretation, two 'crisis' cycles, one at the beginning of the sample period (2000-2003) and the other at the end (2015), are separated by a long 'normal' cycle (2003-2014). In the last part of the sample (2016-2018Q2), analysed in a prediction exercise, the economy appears to have gradually returned to a 'normal' cycle. The 'crisis' cycles occurred when the Brazilian economy was under various types of stress and inflation expectations were not well anchored. In some instances this economic strain was due to external factors, such as the emerging markets confidence runs of 2000-2001. In other cases, political facts such as the crisis of 2002, triggered by uncertainty during the presidential elections, or the political crisis of 2015, appear to be related to exchange rate shocks and a higher level of pass-through. More importantly, our evidence suggests that central bank credibility may act to moderate the effect of pass-through. The two 'crisis' cycles occur in periods when inflation expectations were anchored well beyond the inflation target. We would point in particular to the transition which occurred in 2016-2017 when the new board of the Central Bank of Brazil took office. Inflation expectations were adjusted to a lower level, and, at the same time, the economy returned to a low pass-through regime.

We conclude that the overall results of the MS model are extremely useful for economic analysis and interpretation of exchange rate pass-through dynamics and its nonlinear effects. The model provides relevant information for inflation forecast, especially during large exchange rate shocks, when there is more uncertainty about the effect of the pass-through. For example, the econometrician forecasting inflation with a linear model would assume a $7.6 \%$ level of passthrough in the long run. However, if the econometrician is using a nonlinear model of the type we employ, there is room for a more subtle interpretation. If the economy is under a 'crisis' regime, the MS model indicates that the expected 
pass-through is substantially higher, at $10.35 \%$. However, under a 'normal' regime, one could expect the long-run pass-through to be roughly null, at $0.57 \%$. The difference between the two model types has obvious consequences for policy analysis and design. Finally, our findings underscore the importance of assessing regime switching in certain structural parameters of the Brazilian economy in new Keynesian models, corroborating, to some extent, Gonçalves et al. (2016).

\section{Appendix is available at \\ http://www.cbr.ru/eng/money-and-finance; dx.doi.org/10.31477/rjmf.201901.36}

\section{References}

Adolfson, M., Laséen, S., Lindé, J. and Villani, M. (2007). Bayesian Estimation of an Open Economy DSGE Model with Incomplete Pass-Through. Journal of International Economics, 72(2), pp. 481-511.

Albuquerque, C. R. and Portugal, M. S. (2005). Pass-Through from Exchange Rate to Prices in Brazil: An Analysis Using Time-Varying Parameters for the 1980-2002 Period. Revista de Economia, 12(1), pp. 17-73.

Altug, S. and Çakmakli, C. (2016). Forecasting Inflation Using Survey Expectations and Target Inflation: Evidence for Brazil and Turkey. International Journal of Forecasting, 32(1), pp. 138-153.

Alves, S. A. L. and Areosa, W. D. (2005). Targets and Inflation Dynamics. Banco Central do Brasil Working Papers Series, N 100.

Areosa, W. D. and Medeiros, M. (2007). Inflation Dynamics in Brazil: the Case of a Small Open Economy. Brazilian Review of Econometrics, 27(1), pp. 131-166.

Arruda, E., Ferreira, R. and Castelar, I. (2011). Modelos Lineares e não Lineares da Curva de Phillips para Previsão da Taxa de Inflação no Brasil. Revista Brasileira de Economia, 65(3), pp. 237-252.

Baele, L., Bekaert, G., Cho, S., Inghelbrecht, K.and Moreno, A. (2015). Macroeconomic Regimes. Journal of Monetary Economics, 70, pp. 51-71.

Baharumshah, A. Z., Soon, S. V. and Wohar, M. E. (2017). Markov-Switching Analysis of Exchange Rate Pass-Through: Perspective from Asian Countries. International Review of Economics and Finance, 51, pp. 245-257.

Ball, L. and Cecchetti, S. (1990). Inflation and Uncertainty at Short and Long Horizons. Brookings Papers on Economic Activity, 1, pp. 215-254.

Banco Central do Brasil (2015). Relatório de Inflação (Inflation Report), 17(2).

Belaisch, A. (2003). Exchange Rate Pass-Through in Brazil. IMF Working Papers, N 141.

Bellone, B. (2005). Classical Estimation of Multivariate Markov-Switching Models Using MSVARlib. EconWPA, Econometrics, N 0508017.

Bianchi, F. (2013). Regime Switches, Agents' Beliefs, and Post-World War II US Macroeconomic Dynamics. Review of Economic Studies, 80(2), pp. 463-490. 
Brunner, A. D. and Hess, G. D. (1993). Are Higher Levels of Inflation Less Predictable? A State-Dependent Conditional Heteroscedasticity Approach. Journal of Business and Economic Statistics, 11(2), pp. 187-197.

Carneiro, D. D., Monteiro, A. M. D. and Wu, T. Y. H. (2004). Mecanismos Não-Lineares de Repasse Cambial Para o IPCA. Revista de Economia e Administração, 3(1), pp. 1-14.

Cho, S. (2014). Characterizing Markov-Switching Rational Expectation Models. Available at SSRN: https://ssrn.com/abstract $=1468331$.

Cho, S. and Moreno, A. (2011). The Forward Method as a Solution Refinement in Rational Expectations Models. Journal of Economic Dynamics and Control, 25(3), pp. 257-327.

Correa, A. D. S. and Minella, A. (2010). Nonlinear Mechanisms of the Exchange Rate Pass-Through: A Phillips Curve Model with Threshold for Brazil. Revista Brasileira de Economia, 64(3), pp. 231-1243.

Da Silveira, M. A. C. (2008). Using a Bayesian Approach to Estimate and Compare New Keynesian DSGE Models for the Brazilian Economy: The Role for Endogenous Persistence. Revista Brasileira de Economia, 62(3), pp. 333-357.

De Castro, M. R., Gouvea, S. N., Minella, A., dos Santos, R. C and Souza-Sobrinho N.F. (2015). SAMBA: Stochastic Analytical Model with a Bayesian Approach. Brazilian Review of Econometrics, 35(2), pp. 103-170.

De Mendonça, H. F. and Tiberto, B. P. (2017). Effect of Credibility and Exchange Rate Pass-Through on Inflation: An Assessment for Developing Countries. International Review of Economics and Finance, 50, pp. 196-244.

Di Sanzo, S. (2009). Testing for Linearity in Markov Switching Models: A Bootstrap Approach. Statistical Methods and Applications, 18(2), pp. 153-168.

Dixit, A. (1989). Hysteresis, Import Penetration, and Exchange Rate Pass-Through. The Quarterly Journal of Economics, 104(2), pp. 205-228.

Donayre, L. and Panovska, I. (2016). State-Dependent Exchange Rate Pass-Through Behavior. Journal of International Money and Finance, 64(C), pp. 170-195.

Engle, R. F. (1982). Autoregressive Conditional Heteroscedasticity with Estimates of the Variance of United Kingdom Inflation. Econometrica, 50(4), pp. 987-1007.

Farmer, R. E. A., Waggoner, D. F. and Zha, T. (2011). Minimal State Variable Solutions to Markov-Switching Rational Expectations Models. Journal of Economic Dynamics and Control, 35(12), pp. 2150-2166.

Fasolo, A. M. and Portugal, M. S. (2004). Imperfect Rationality and Inflationary Inertia: A New Estimation of the Phillips Curve for Brazil. Estudos Econômicos, 34(4), pp. 725-776.

Fernández-Villaverde, J., Guerrón-Quintana, P. and Rubio-Ramírez, J. F. (2010). Fortune or Virtue: Time-Variant Volatilities versus Parameter Drifting in US Data. NBER Working Paper, N 15928.

Figueiredo, F. M. R. and Gouvea, S. (2011). Repasse Cambial para a Inflação: O Papel da Rigidez de Preços. In: Banco Central do Brasil, Dez Anos de Metas para Inflação 1999-2009. Brasília: Banco Central do Brasil, pp. 127-168. 
Furlani, L. G. C., Portugal, M. S. and Laurini, M. P. (2010). Exchange Rate Movements and Monetary Policy in Brazil: Econometric and Simulation Evidence. Economic Modelling, 7(1), pp. 284-295.

Goldfajn, I. and Werlang, S. R. C. (2000). The Pass-Through from Depreciation to Inflation: A Panel Study. Banco Central do Brasil Working Papers Series, N 5.

Gonçalves, C. C. S., Portugal, M. S. and Arágon, E. K. S. B. (2016). Assessing Brazilian Macroeconomic Dynamics Using a Markov-Switching DSGE Model. EconomiA, 17(1), pp. 23-42.

Hamilton, J. D. (1989). A New Approach to the Economic Analysis of Nonstationary Time Series and the Business Cycle. Econometrica, 57(2), pp. 357-384.

Hamilton, J. D. (1994). Time Series Analysis. Princeton University Press, 1994.

Hamilton, J. D. (2005). What's Real about the Business Cycle? Federal Reserve Bank of St. Louis Review, 87(4), pp. 435-452.

Hamilton, J. D. (2014). Macroeconomic Regimes and Regime Shifts. In: J. B. Taylor and H. Uhlig, eds., Handbook of Macroeconomics. Elsevier, Vol. 2, pp. 163-201.

Holmes, M. J. (2009). The Response of Exchange Rate Pass-Through to the Macroeconomic Environment. The Open Business Journal, 2, pp. 1-6.

Iboshi, H. (2016). Monetary Policy Regime Shifts under the Zero Lower Bound: An Application of a Stochastic Rational Expectations Equilibrium to a Markov Switching DSGE Model. Economic Modelling, 52(A), pp. 186-205.

Justiniano, A. and Primiceri, G. E. (2008). The Time-Varying Volatility of Macroeconomic Fluctuations. American Economic Review, 98(3), pp. 604-41. doi: 10.1257/aer.98.3.604

Khemiri, R. and Ali, M. S. B (2013). Exchange Rate Pass-Through and Inflation Dynamics in Tunisia: A Markov-Switching Approach. Economics: The Open-Access, Open-Assessment E-Journal, 7(43), pp. 1-30. doi: 10.5018/economics-ejournal.ja.2013-43

Kim, C.-J. and Nelson, C. R. (1999). Has the US Economy Become More Stable? A Bayesian Approach Based on a Markov-Switching Model of the Business Cycle. Review of Economics and Statistics, 81(4) pp. 608-16.

Kohlscheen, E. (2010). Emerging Floaters: Pass-Throughs and (Some) New Commodity Currencies. Banco Central do Brasil Working Papers Series, N 224.

Krolzig, H. M. (1997). Markov-Switching Vector Autoregressions: Modelling, Statistical Inference and Application to Business Cycle Analysis. Berlin: Springer-Verlag, 1997.

Liu, P. and Mumtaz, H. (2010). Evolving Macroeconomic Dynamics in a Small Open Economy: An Estimated Markov-Switching DSGE Model for the United Kingdom. Bank of England Working Paper, N 397.

Mankiw, N. G. and Reis, R. (2002). Sticky Information versus Sticky Prices: A Proposal to Replace the New Keynesian Phillips Curve. Quarterly Journal of Economics, 117(4), pp. 251-301.

Mazali, A. A. and Divino, J. A. (2010). Real Wage Rigidity and the New Phillips Curve: The Brazilian Case. Revista Brasileira de Economia, 64(3), pp. 291-306. 
Minella, A., De Freitas, P. S., Goldfajn, I. and Muinhos, M. K. (2003). Inflation Targeting in Brazil: Constructing Credibility under Exchange Rate Volatility. Banco Central do Brasil Working Papers Series, N 77.

Montes, G. C., and Ferreira, C. F. (2018). Does Monetary Policy Credibility Mitigate the Effects of Uncertainty about Exchange Rate on Uncertainties about Both Inflation and Interest Rate? International Economics and Economic Policy, pp. 1-30.

Nogueira Jr, R. P. (2010). Inflation Environment and Lower Exchange Rate Pass-Through in Brazil: Is there a Relationship? Revista Brasileira de Economia, 64(1), pp. 49-56.

Oliveira, L. and Feijó, F. T. (2015). Curva de Phillips com Mudança de Regime Markoviano: Uma Análise da Economia Brasileira para o Período 1995-2014.

Annals of the XLIII National Economic Meeting ANPEC. Florianópolis, SC, Brazil. December.

Owyang, M. T. (2001). Persistence, Excess Volatility, and Volatility Clusters in Inflation. Federal Reserve Bank of St. Louis Review, 83(6), pp. 41-52.

Palma, A. A. and Portugal, M. S. (2014). Preferences of the Central Bank of Brazil under the Inflation Targeting Regime: Estimation using a DSGE Model for a Small Open Economy. Journal of Policy Modeling, 36(5), pp. 824-839.

Pimentel, D. M., Luporini, V. and Modenesi, A. M. (2016). Assimetrias no Repasse Cambial para a Inflação: Uma Análise Empírica para o Brasil (1999 a 2013). Estudos Econômicos (São Paulo), 46(2), pp. 343-372.

Rodrigues, W. G. and Mori, R. (2015). Mudanças de Regimes na Função de Reação do Banco Central do Brasil: Uma Abordagem Utilizando Markov Regime Switching. In: Anais do XLIII Encontro Nacional de Economia ANPEC. Florianópolis, SC, Brazil. December.

Sachsida, A. (2013). Inflação, Desemprego e Choques Cambiais: Uma Revisão da Literatura Sobre a Curva de Phillips no Brasil. Revista Brasileira de Economia, 67(4), pp. 521-531.

Sims, C. (2002). Solving Linear Rational Expectations Models. Computational Economics, 20(1-2), pp. 1-20.

Sims, C. and Zha, T. (2006). Were There Regime Switches in US Monetary Policy? American Economic Review, 91(1), pp. 54-81.

Taylor, J. (2000). Low Inflation, Pass-Through and the Pricing Power of Firms. European Economic Review, 44(7), pp. 1389-1408.

Tombini, A. A. and Alves, S. A. L. (2006). The Recent Brazilian Disinflation Process and Costs. Banco Central do Brasil Working Papers Series, N 109.

Tristão, T. S. And Torrent, H. S. (2015). Relações não Lineares na Curva de Phillips: Uma Abordagem Semi-Paramétrica. Economia Aplicada, 19(4), pp. 679-703.

Vieira, H. P. and Pereira, P. V. (2013). A Study of the Brazilian Business Cycles (1900-2012). Brazilian Review of Econometrics, 33(2), pp. 123-143.

Winkelried, D. (2014). Exchange Rate Pass-Through and Inflation Targeting in Peru. Empirical Economics, 46(4), pp. 1181-1196. 